\title{
THE STUDY OF CORRELATION BETWEEN FORWARD HEAD POSTURE AND NECK PAIN IN IRANIAN OFFICE WORKERS
}

\author{
PARISA NEJATI ${ }^{1}$, SARA LOTFIAN ${ }^{1}$, AZAR MOEZY $^{1}$, and MINA NEJATI ${ }^{2}$ \\ ${ }^{1}$ Rasoul Akram Hospital, Iran University of Medical Science, Tehran, Iran \\ Department of Sports Medicine \\ ${ }^{2}$ Tehran University of Medical Sciences, Tehran, Iran \\ student
}

\begin{abstract}
Objectives: Factors such as prolonged sitting at work or improper posture of head during work may have a great role in neck pain occurrence among office employees, particularly among those who work with computers. Although some studies claim a significant difference in head posture between patients and pain-free participants, in literature the forward head posture (FHP) has not always been associated with neck pain. Since head, cervical and thoracic postures and their relation with neck pain has not been studied in Iranian office employees, the purpose of this study was to investigate the relationship between some work-related and individual factors, such as poor posture, with neck pain in the office employees. Material and Methods: It was a cross-sectional correlation study carried out to explore the relationship between neck pain and sagittal postures of cervical and thoracic spine among office employees in forward looking position and also in a working position. Forty-six subjects without neck pain and 55 with neck pain were examined using a photographic method. Thoracic and cervical postures were measured using the high thoracic (HT) and craniovertebral (CV) angles, respectively. Results: High thoracic and CV angles were positively correlated with the presence of neck pain only in working position $(\mathrm{p}<0.05)$. In forward looking position, there was no statistically significant difference between the 2 groups $(\mathrm{p}>0.05)$. Conclusions: Our findings have revealed that office employees had a defective posture while working and that the improper posture was more severe in the office employees who suffered from the neck pain.
\end{abstract}

Key words:

Neck pain, Craniovertebral angle, Forward head posture, High thoracic angle, Office employee

\section{INTRODUCTION}

Neck pain is a common disorder characterized by pain, discomfort or soreness experienced in a region between the inferior margin of the occipital bone and T1 [1].

Prevalence of neck pain in employees is not the same all over the world. In western countries it has been reported to be between $34 \%$ and $54 \%$, with Scandinavian countries having higher mean estimates than the rest of
Europe and Asia [1,2]. According to a telephone survey, in Hong Kong, $64 \%$ of the respondents had experienced neck pain in the past 12 months [3]. The prevalence of neck pain in 282 office workers working with computers in 4 different companies in Sudan was reported in 2008 by Eltayeb to be $64 \%$ [4]. One of the highest prevalence rates of neck pain in Asia and Pacific area has been reported in Iran with a considerable difference in urban $(13.4 \%)$

The study was granted by Tehran University of Medical Sciences (grant no. 90-1-30-13153). Manager of grant: Abbas Motavalian, Ph.D. of epidemiology.

Received: June 10, 2014. Accepted: August 26, 2014.

Corresponding author: S. Lotfian, Rasoul Akram Hospital, Iran University of Medical Science, No 1, Niayesh Street, Shahrara, 1445634443 Tehran, Iran (e-mail: saralotfiyan@yahoo.com). 
and rural (17.9\%) regions [5-7]. Neck pain was a more common complaint in Iranian dentists (28-61\%) who had a flexed neck posture for a long period of time [8-10]. The prevalence of neck pain among Iranian office employees has not been exactly determined.

Forward head posture (FHP) is an epidemic that has become more prevalent in modern times. It is described as carrying the head forward of the center of the shoulder. As the head moves forward, the center of gravity shifts. To compensate for this shift in the center of gravity, upper body drifts backward and shoulders slump forward so that the head is placed anterior to the trunk [11,12]. It is caused by several factors including: sleeping with head elevated too high, extended use of computers, lack of the developed back muscle strength, etc. The widespread use of computers in offices in the recent decade has led to raised daily time that a person spends using a personal computer. These changes may be accompanied by a poor posture and the resultant neck pain. The relation between FHP and neck pain is still debatable. In literature, the forward head posture has not always been associated with neck pain [13], even though some evidence claims a significant difference in head posture between the patients and pain-free participants [14-17].

Neck posture is defined as the alignment of cervical spine at a particular time. It is examined in different positions, the most common being standing and sitting [18,19]. Clinicians usually estimate the severity of the abnormal posture subjectively and categorize it as slight, moderate, or severe, based on their own visual estimates. Several studies have produced estimates of head, neck and thoracic spine relative positions in neutral position, but there is still insufficient data on angles in other positions including those during work with a computer. Thoracic kyphosis accompanied by high cervical spine extension results in a rounded shoulder and is related to neck pain [20].

Although data on specific costs of work-related sick leave, medical consumption, and neck pain in Iran are not available, it is clear that prevention of musculoskeletal problems like neck pain would be of great benefit. As neck pain could become a chronic and disabling symptom, discovering and controlling risk factors seems to be a reasonable prevention strategy. Improper posture could be improved by education and proper reminders to decrease the prevalence of neck pain and increase the quality of life among office employees. This study aims at quantification of postural changes of head and cervical, and thoracic spine in the office employees while working with a computer in order to determine the relationship between neck pain and improper postures.

\section{MATERIAL AND METHODS}

A cross-sectional study was designed to compare the head, neck and upper thoracic postures in the office employees with and without neck pain over the years 2011-2012. The Research Ethics Committee of Tehran University of Medical Sciences approved the study.

The study population was the entire population of the full time working employees of Iran University of Medical Science, whose job included office work with a desktop computer. After general invitation, a total of 159 employees participated in the baseline survey. A written informed consent was obtained from all the subjects. All the office employees with chronic pain, ache or soreness experienced in a region between the inferior margin of the occipital bone and $\mathrm{T} 1$ for a period of over 3 months were included in the symptomatic group, while all the other employees were included in the asymptomatic group. The participants with acute neck pain, intermittent neck pain, transient neck pain or any radiation of the pain to the upper extremity (neurological origin of the pain), presence of cervical trauma history, fracture, surgery, and also the employees who did not want to have their pictures taken were excluded from the study. Therefore, the study finally included 101 employees.

Postural assessment was assessed for each employee individually in his/her office by a researcher. Demographic 
data such as gender, age, height, weight, body mass index (BMI), location and duration of pain (if any), working day hours, hours of driving per day, history of previous treatments (in symptomatic subjects) and history of physical activity were recorded. In this study, the researchers attempted to keep the subject's privacy during postural assessment. All the measurements were performed in the office and at the participants' own desks between the 4th and 5 th $\mathrm{h}$ of work by one researcher. A surgical cap and mask were provided for each participant to cover their hair and face in order not to be identifiable in the photos. The participants were asked to expose their neck and upper thoracic spine. Spinous processes of $\mathrm{C} 7$ and $\mathrm{T} 7$ were palpated and 2 adhesive markers were attached over the midpoint of the most prominent parts of $\mathrm{C} 7$ and T7. Another marker was attached on tragus (Figure 1).

Three prominent markers were stuck in order to help the researchers find the points in the photos during analysis. Firstly, the workers were asked to type a common text on their computers for about $5 \mathrm{~min}$ and then during the last minutes of typing the researcher took a picture without alarm. The participants were asked to be in a position they were usually in at work. The 2 nd picture was taken when the researcher asked the employees to sit on their chairs and look forward ahead at a fixed point on the wall, $120 \mathrm{~cm}$ above the ground. Before taking the 2nd photograph, the participant was asked to completely flex, extend the neck 3 times and put the head in a quite comfortable position [14]. The 2 photos were taken at a distance of $80 \mathrm{~cm}$ to record sagittal sitting postures at the right or left side of the participant depending on the location of his/her desk. The lens of the camera were adjusted at the level of external auditory meatus by adjusting the height of the camera tripod. All the photos were taken using the Nikon Coolpix P4 (8.1 Mpx) camera by one researcher.

Photographic data were analyzed by "Body Posture Analyzer" software made by Danesh Salar Company of Iran. On the photos that were transmitted by this software a line

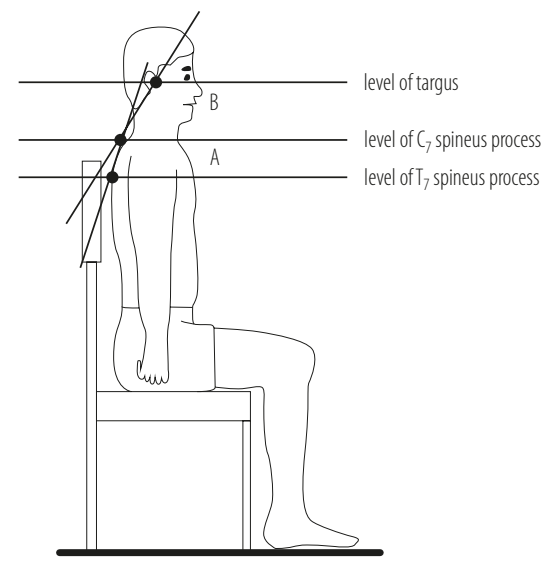

A - high thoracic angle; B - craniovertebral angle.

Fig. 1. Measurement of sagittal posture of thoracic and cervical spine

was drawn from tragus to $\mathrm{C} 7$ and another line from $\mathrm{C} 7$ to $\mathrm{T} 7$. According to Figure 1, the high thoracic angle (HTA) and craniovertebral angle (CVA) were calculated by this software. High thoracic angle was the angle between horizontal line through the spinous process of $\mathrm{T} 7$ and a line connecting the spinous process of $\mathrm{T} 7$ to $\mathrm{C}$, and CVA is the angle between horizontal line through the spinous process of $\mathrm{C} 7$ and a line connecting $\mathrm{C} 7$ to tragus. Inter rater and intra rater reliability of these methods have been reported before in the study of Lau et al. [20]. According to that study, they ranged from 0.81 to 0.86 for high thoracic angle and from 0.81 to 0.87 for craniovertebral angle, respectively.

The data were analyzed using the Statistical Package for the Social Sciences (SPSS) software (v 16). Descriptive statistics (mean, standard deviation, range) were computed for each study variable. Univariate and multivariate analyses were performed. The differences between the groups were calculated through cross-tabulations and an independent sample's t-test.

\section{RESULTS}

Among 101 office workers (46 subjects in the asymptomatic group, 55 subjects in the symptomatic group) who participated in the study, $73 \%$ were female. Sex was not different 
between the 2 groups. The mean age \pm standard deviation (SD) of the participants was $39 \pm 8$ years without any significant difference between the 2 groups ( $p=0.847$ ). Work duration of employees was $14 \pm 8$ years with no difference between the symptomatic and asymptomatic groups $(p=0.415)$. Weight, height, and BMI of our subjects were respectively $69.2 \pm 11.9 \mathrm{~kg}, 165.0 \pm 8.4 \mathrm{~cm}$, and 25.3 \pm 3.7 , which was comparable in both groups.

In the asymptomatic group, $30.6 \%$ (26/46) of the participants worked fewer than $4 \mathrm{~h}, 17.6 \%$ (15/46) worked 4-8 h, and $3.6 \%$ (3/46) worked over $8 \mathrm{~h}$ with a personal computer on a working day. In the symptomatic group, the percentages of the subjects who worked fewer than $4 \mathrm{~h}$, 4-8 $\mathrm{h}$ and over $8 \mathrm{~h}$ were: $21.2 \%$ (18/55), 22.4\% (19/55), and $4.7 \%(4 / 55)$, respectively. There was no significant correlation between the numbers of working hours a day and neck pain $(p=0.322)$. Also, there was no significant correlation between driving hours a day, duration of pain, previous treatments and neck pain. Additionally, there was no positive or negative correlation between physical activity history and neck pain. Comparisons between the 2 groups are summarized in Table 1.

As shown in Table 2, Figure 2 and Figure 3, there were statistically significant differences in CVA and HTA between the symptomatic and asymptomatic groups only during work. In other words, the participants with neck pain revealed a poor posture of cervical and thoracic spine at work. There were also correlations between sagittal posture of cervical and thoracic spine (CVA, HTA) and neck pain.

\section{DISCUSSION}

The findings of the present study have revealed that office employees had a more improper posture while working with a computer versus sitting with forward looking (not

Table 1. Comparison of demographic data between the office employees with and without neck pain

\begin{tabular}{|c|c|c|c|}
\hline \multirow{2}{*}{ Variable } & \multicolumn{2}{|c|}{$\begin{array}{c}\text { Office employees } \\
(\mathrm{N}=101)\end{array}$} & \multirow{2}{*}{$\mathrm{p}$} \\
\hline & $\begin{array}{l}\text { with neck pain } \\
(\mathrm{N}=55)\end{array}$ & $\begin{array}{l}\text { without neck pain } \\
\qquad(\mathrm{N}=46)\end{array}$ & \\
\hline Female & 40.00 & 33.00 & 0.096 \\
\hline Age (years) (M) & 38.00 & 39.00 & 0.847 \\
\hline Weight (kg) (M) & 70.00 & 68.00 & 0.918 \\
\hline Height (cm) (M) & 169.00 & 165.00 & 0.503 \\
\hline Body mass index (M) & 24.56 & 25.18 & 0.589 \\
\hline Seniority (years) (M) & 12.00 & 14.00 & 0.415 \\
\hline \multicolumn{4}{|l|}{ Working $(\%)$} \\
\hline$<4$ h/day & 21.20 & 30.60 & 0.533 \\
\hline 4-8 h/day & 22.40 & 17.60 & 0.814 \\
\hline$>8 \mathrm{~h} /$ day & 4.70 & 3.60 & 0.592 \\
\hline Driving (min/day) & 30.00 & 39.00 & 0.604 \\
\hline Physical activity (h/week) & 1.00 & 0.50 & 0.087 \\
\hline \multicolumn{4}{|l|}{ Duration of pain (n) } \\
\hline$<1$ year & 32.00 & - & - \\
\hline$>1$ year & 23.00 & - & - \\
\hline
\end{tabular}

$\mathrm{M}-$ mean. 
Table 2. Comparison of craniovertebral angle (CVA)* and high thoracic angle (HTA $)^{* *}$ between the office employees with and without neck pain

\begin{tabular}{|c|c|c|c|}
\hline \multirow[b]{2}{*}{ Position } & \multicolumn{2}{|c|}{ Office employees } & \multirow[b]{2}{*}{$\mathrm{p}$} \\
\hline & $\begin{array}{l}\text { with neck pain } \\
\quad(\mathrm{N}=55)\end{array}$ & $\begin{array}{l}\text { without neck pain } \\
\quad(\mathrm{N}=46)\end{array}$ & \\
\hline \multicolumn{4}{|c|}{ Looking forward (neutral position) $(\mathrm{M} \pm \mathrm{SD})$} \\
\hline $\operatorname{CVA}\left({ }^{\circ}\right)$ & $37.1 \pm 7.8$ & $37.70 \pm 8.20$ & 0.70 \\
\hline $\operatorname{HTA}\left({ }^{\circ}\right)$ & $118.3 \pm 7.9$ & $117.00 \pm 8.60$ & 0.43 \\
\hline \multicolumn{4}{|c|}{ Working with computer $(\mathrm{M} \pm \mathrm{SD})$} \\
\hline $\operatorname{CVA}\left({ }^{\circ}\right)$ & $23.0 \pm 10.7$ & $28.40 \pm 12.40$ & 0.04 \\
\hline HTA $\left({ }^{\circ}\right)$ & $129.8 \pm 10.3$ & $124.39 \pm 10.20$ & 0.02 \\
\hline
\end{tabular}

* Smaller angle indicates forward head posture (FHP).

** Greater angle indicates FHP, thoracic khyphosis.

$\mathrm{M}$ - mean; SD - standard deviation.

a working) position, and that the defective posture in the working position was more severe in the symptomatic group. It may be due to poor ergonomics of chair, desk, computers position and also lack of attention paid to body position during work. We have not found any relationship

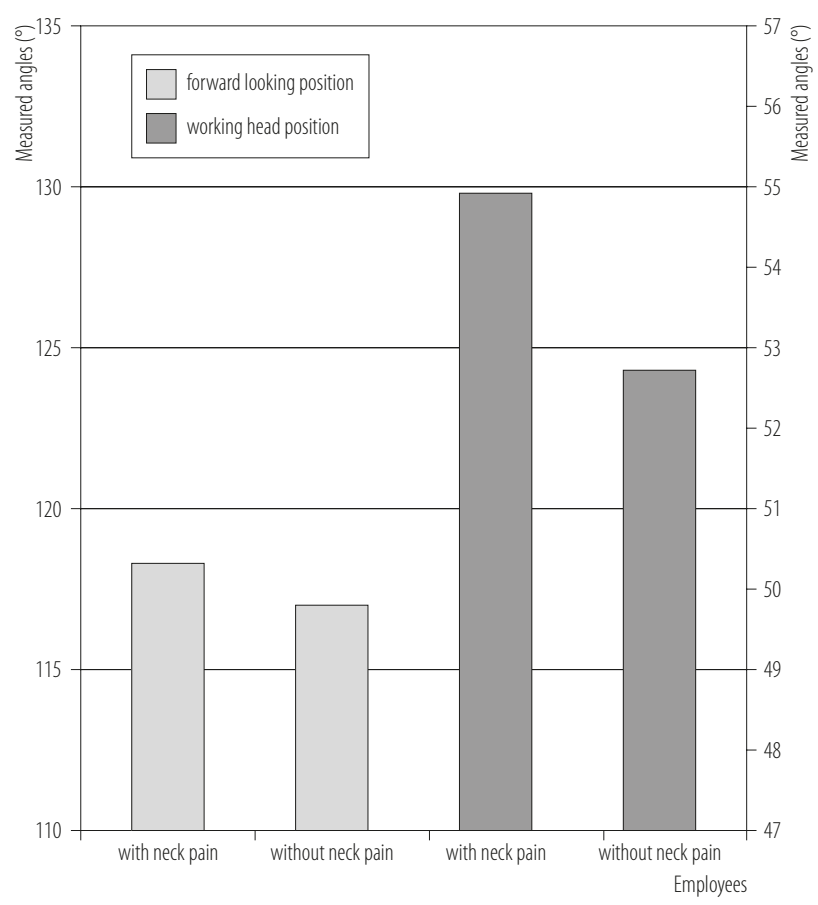

Fig. 2. Comparison of high thoracic angle between the office employees with and without neck pain in 2 positions between individual factors, such as gender, age, daily work hours, etc. with neck pain.

A systematic review that the included research of 4 studies has showed that the available evidence for the relationship between workplace design and neck pain is inconclusive [21]

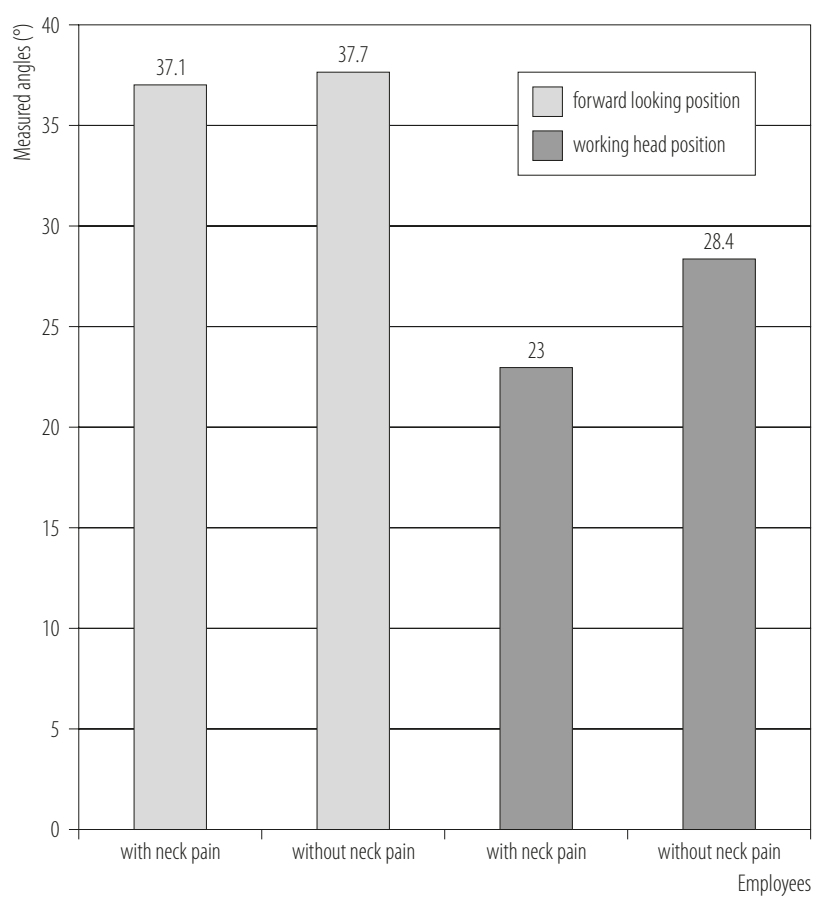

Fig. 3. Comparison of craniovertebral angle between the symptomatic and asymptomatic office employees in 2 positions 
and that further research is needed. Lack of awareness of posture while working among employees is important in causing improper posture of head and neck; so paying attention to head and neck posture during work might be a good way to decrease the poor posture. It can be introduced into the office environment by feedback methods, mirror or alarming instruments.

In a systematic review, 4 cross-sectional studies (including 2 high-quality studies) were reviewed, and the results of all the works showed that there was a significant relationship between an individual's posture and his/her neck pain [21]. The results of our study showed that the difference concerning CVA and HTA between the 2 groups in the not working position (looking forward) was not statistically significant. The difference in CVA and HTA was significant when the measurement was taken in the working position $\left(23^{\circ}, 129^{\circ}\right.$ in the symptomatic group and $28^{\circ}, 124^{\circ}$ in the asymptomatic group). Inappropriate postures of office workers, which are worse in the symptomatic subjects may be a possible explanation for this finding. According to our results, the subjects with lower CVA (forward head posture) and higher HTA (forward head posture, thoracic kyphosis) in the working position experienced more neck pain.

The amount of CVA $(37.1 \pm 7.8)$ and HTA $(118.3 \pm 7.9)$ in both groups was smaller than the average amounts of CVA (48.9 \pm 4.3$)$ and HTA (116.3 \pm 4.3$)$ measured in populations from other countries [11,20,22,23], which is a notable point. In a survey among Chinese office employees in 2008, the prevalence of forward head posture was reported to be as high as $25 \%$ [24].

One of the non-invasive methods to evaluate head and back posture is a photography-based technique that was used in this study. The reliability of the assessment has been reported as satisfactory in the sagittal view [19,20,25-27].

According to the results of Cagnie et al. study [28], it has been found that there is a positive correlation between duration of computer work and neck pain. Other studies $[2,29,30]$ that were published before 2000 showed that if duration of sitting at a desk is longer than $5 \mathrm{~h} /$ day, it is considered as a risk factor for neck pain. In contrast to these findings, a systematic review of the 3 studies has found that there was no significant relationship between the duration of sitting and neck pain [21]. According to Mostamand study [31], there has been no significant difference between cervical posture in Iranian dentists working 5-8 h/day and those working $8-12 \mathrm{~h} /$ day. Based on our findings, there was no relationship between hours of work with a computer and neck pain $(\mathrm{p}=0.322)$.

In a prospective study with a 3-year follow-up of more than 1334 employees by Ariens et al., it has been observed that there was a strong relationship between duration of sitting in working hours and neck pain in such a way that if one was in a sitting position for over $95 \%$ of their working hours, the probability of suffering from neck pain increased [29]. According to the results obtained in the present study, it was observed that $51.8 \%$ of the employees spent less than $50 \%$ of their working hours on working with personal computers. Actual low working time with a personal computer in our study may be the reason for the lack of a significant difference compared to Ariens's research.

In the present study, $8.3 \%$ of the office employees worked with personal computers over $8 \mathrm{~h}$ daily. These were employees who worked in units with higher workload, requiring high concentration and focus, imposing greater psychological stress and higher unawareness of posture. Since psychological stress was investigated subjectively by self-assessment of the personnel, the correlation between stress and neck pain is not very accurate in this study. However, we could not use data on stress for the purpose of the analysis. In the future studies, in order to determine the relationship between psychological stress and posture it will be better to evaluate psychological stress using job stress questionnaire. According to the results of our study, 
a hypothesis can be introduced saying that if duration of sitting in front of a personal computer is longer but with a proper sitting posture, the probability of neck pain is reduced. Future research with respect to this aspect is recommended.

According to previous literature [24,28,30,31], FHP is more prevalent in women compared to men, while our work showed no difference in terms of FHP prevalence in men and women (there was no difference in HTA and CVA between females and males). A systematic review of the results of 5 studies has indicated that there was no correlation between participation in various sports and recreational exercises and neck pain [21]. Cagnie [28] has found that physical activity decreases the likelihood of having neck pain $(\mathrm{OR}=1.85,95 \% \mathrm{CI}$ : 1.14-2.99). Findings of our study showed that the subjects had no regular sport activities and few of them occasionally exercised at the weekend, which has been negligible, therefore, no positive or negative correlation could be sought, underlining the need for further research.

Another variable that has been investigated in majority of the studies is the relationship between driving hours and the prevalence of neck pain. In 2 studies, one high quality and other low quality, no evidence has been found to establish driving as a risk factor for neck pain [21]. In the present study, people on average drove half an hour a day (mean $=0.524)$. No significant difference was observed between the asymptomatic and symptomatic groups in terms of driving hours.

Considering the fact that there is no accurate statistics for inability or need to rest in university office employees, further work may signify the importance of informing office workers of proper posture while working with computers. It can be hoped then, that by appropriate management and planning as well as allocation of necessary funds, proper posture observance in employees will be established as the 1st step in planning preventive strategies for most musculoskeletal problems.
According to a study by Lau et al., there was a positive relationship between sagittal postures of thoracic and cervical spine and neck pain; the people with neck pain had a higher HTA $\left(7.34^{\circ}\right)$ compared to the asymptomatic people [20]. In our study, it was observed that HTA was correlated with neck pain. High thoracic angle was higher in the symptomatic group versus the people without neck pain. Therefore, it should be emphasized that it is necessary to evaluate the thoracic spine in people with neck pain. Prophylactic interventions for modifying CVA and HTA could be recommended as an effective way of decreasing neck pain.

This study had several limitations. A major limitation of our work is that we have not applied standard and valid psychological questionnaires to assess the subjects' stress and mental status. Also ergonomic factors have not been included in this study, which is its another limitation.

\section{CONCLUSIONS}

According to this study, incorrect postures of head, cervical and thoracic spine were related to neck pain only in working position and there was no relationship between neck pain and spinal posture in forward looking position.

\section{REFERENCES}

1. Fejer R, Kyvik KO, Hartvigsen J. The prevalence of neck pain in the world population: A systematic critical review of the literature. Eur Spine J. 2006;15(6):834-48, http://dx.doi. org/10.1007/s00586-004-0864-4.

2. Côté P, Cassidy JD, Carroll L. The factors associated with neck pain and its related disability in the Saskatchewan population. Spine. 2000;25(9):1109-17.

3. Chiu TTW, Leung ASL. Neck pain in Hong Kong: A telephone survey on prevalence, consequences, and risk groups. Spine. 2006;31(16):E540-4, http://dx.doi.org/10.1097/01.brs. 0000225999.02326.ad. 
4. Eltayeb SM, Staal JB, Hassan AA, Awad SS, de Bie RA. Complaints of the arm, neck and shoulder among computer office workers in Sudan: A prevalence study with validation of an Arabic risk factors questionnaire. Environ Health. 2008;7:338, http:/dx.doi.org/10.1186/1476-069X-7-33.

5. Davatchi F. Rheumatic diseases in the APLAR region. J Rheum. 2006;9:5-10, http://dx.doi.org/10.1111/j.1479-8077. 2006.00177.x.

6. Davatchi F, Jamshidi AR, Banihashemi AT, Gholami J, Forouzanfar MH, Akhlaghi M, et al. WHO-ILAR COPCORD study (stage 1, urban study) in Iran. J Rheumatol. 2008;35(7):1384-90.

7. Davatchi F, Banihashemi AT, Gholami J, Faezi ST, Forouzanfar MH, Salesi M, et al. The prevalence of musculoskeletal complaints in a rural area in Iran: A WHO-ILAR COPCORD study (stage 1, rural study) in Iran. Clin Rheumatol. 2009;28(11):1267-74, http://dx.doi.org/10.1007/s10067009-1234-8.

8. Pargali N, Jowkar N. Prevalence of musculoskeletal pain among dentists in Shiraz, Southern Iran. Int J Occup Environ Med. 2010;1(2):69-74.

9. Aarabi A, Zamiri B, Mohammadinezhad C, Rahmanian F, Mahmoudi H. Musculoskeletal disorders in dentists in Shiraz, southern Iran. Iranian Red Crescent Med J. 2009; 11(4):464-5.

10. Chamani G, Zarei MR, Momenzadeh A, Safizadeh H, Rad M, Alahyari A. Prevalence of musculoskeletal disorders among dentists in Kerman, Iran. J Musculoskelet Pain. 2012;20(3):202-7.

11. Kang JH, Park RY, Lee SJ, Kim JY, Yoon SR, Jung KI. The effect of the forward head posture on postural balance in long time computer based worker. Ann Rehabil Med. 2012;36(1):98-104, http://dx.doi.org/10.5535/ arm.2012.36.1.98.

12. Yip CHT, Chiu TTW, Poon ATK. The relationship between head posture and severity and disability of patients with neck pain. Man Ther. 2008;13(2):148-54, http:// dx.doi.org/10.1016/j.math.2006.11.002.
13. Silva AG, Punt TD, Sharples P, Vilas-Boas JP, Johnson MI. Head posture assessment for patients with neck pain: Is it useful? Int J Ther Rehabil. 2009;16(1):43-53, http://dx.doi.org/10.12968/ijtr.2009.16.1.37939.

14. Fernández-de-las-Peñas C, Alonso-Blanco C, Cuadrado M, Pareja J. Forward head posture and neck mobility in chronic tension-type headache: A blinded, controlled study. Cephalalgia. 2006;26(3):314-9, http://dx.doi.org/ 10.1111/j.1468-2982.2005.01042.x.

15. Pascarelli EF, Hsu YP. Understanding work-related upper extremity disorders: Clinical findings in 485 computer users, musicians, and others. J Occup Rehabil. 2001; 11(1):1-21, http://dx.doi.org/10.1023/A:1016647923501.

16. Silva AG, Punt TD, Sharples P, Vilas-Boas JP, Johnson MI. Head posture and neck pain of chronic nontraumatic origin: A comparison between patients and painfree persons. Arch Phys Med Rehabil. 2009;90(4):66974, http://dx.doi.org/10.1016/j.apmr.2008.10.018.

17. Fernández-de-las-Peñas C, Cuadrado M, Pareja J. Myofascial trigger points, neck mobility and forward head posture in unilateral migraine. Cephalalgia. 2006;26(9):1061-70, http://dx.doi.org/10.1111/j.1468-2982.2006.01162.x.

18. Magee D. Orthopedic physical assessment. 4th ed. St. Louis: Saunders Elsevier; 2006.

19. Neumann DA, Rowan EE. Kinesiology of the musculoskeletal system: Foundations for physical rehabilitation. 5th ed. St. Louis: Mosby; 2002.

20. Lau KT, Cheung KY, Chan MH, Chan KB, Lo KY, Chiu TT. Relationships between sagittal postures of thoracic and cervical spine, presence of neck pain, neck pain severity and disability. Man Ther. 2010;15(5):457-62, http:// dx.doi.org/10.1016/j.math.2010.03.009.

21. Ariëns M, van Mechelen W, Bongers M, Bouter M, van der Wal G. Physical risk factors for neck pain. Scand J Work Environ Health. 2000;26(1):7-19, http:// dx.doi.org/10.5271/sjweh.504.

22. Lau HMC, Chiu TTW, Lam TH. Measurement of craniovertebral angle with electronic head posture instrument: 
Criterion validity. J Rehabil Res Dev. 2010;47(9):911-8, http://dx.doi.org/10.1682/JRRD.2010.01.0001.

23. Agustin CTS, Wilmarth MA, Raymond J, Hilliard TS. The amount and variation of craniovertebral angle changes in college-aged students using one-strapped and two-strapped backpacks and bags. Orthop Pract. 2003;15(3):30-3.

24. Cho CY. Survey of faulty postures and associated factors among Chinese adolescents. J Manipulative Physiol Ther. 2008;31(3):224-9, http://dx.doi.org/10.1016/j.jmpt. 2008.02.003.

25. Paušić J, Pedišić Z, Dizdar D. Reliability of a photographic method for assessing standing posture of elementary school students. J Manipulative Physiol Ther. 2010;33(6):425-31, http://dx.doi.org/10.1016/j.jmpt.2010.06.002.

26. Dunk NM, Lalonde J, Callaghan JP. Implications for the use of postural analysis as a clinical diagnostic tool: Reliability of quantifying upright standing spinal postures from photographic images. J Manipulative Physiol Ther. 2005;28(6): 386-92, http://dx.doi.org/10.1016/j.jmpt.2005.06.006.

27. Ferreira EAG, Duarte M, Maldonado EP, Burke TN, Marques AP. Postural assessment software (PAS/SAPO):
Validation and reliability. Clinics. (Sao Paulo) 2010;65(7): 675-81, http://dx.doi.org/10.1590/S1807-59322010000700005.

28. Cagnie B, Danneels L, van Tiggelen D, de Loose V, Cambier D. Individual and work related risk factors for neck pain among office workers: A cross sectional study. Eur Spine J. 2007;16(5):679-86, http://dx.doi.org/10.1007/ s00586-006-0269-7.

29. Ariëns GA, Bongers PM, Douwes M, Miedema MC, Hoogendoorn WE, van der Wal G, et al. Are neck flexion, neck rotation, and sitting at work risk factors for neck pain? Results of a prospective cohort study. Occup Environ Med. 2001;58(3):200-7, http://dx.doi.org/10.1136/ oem.58.3.200.

30. Briggs A, Straker L, Greig A. Upper quadrant postural changes of school children in response to interaction with different information technologies. Ergonomics. 2004;47(7): 790-819, http://dx.doi.org/10.1080/00140130410001663569.

31. Mostamand J, Lotfi H, Safi N. Evaluating the head posture of dentists with no neck pain. J Bodywork Mov Ther. 2013;17(4):430-3, http://dx.doi.org/10.1016/ j.jbmt.2012.11.002.

This work is available in Open Access model and licensed under a Creative Commons Attribution-NonCommercial 3.0 Poland License - http://creativecommons.org/ licenses/by-nc/3.0/pl/deed.en. 